\title{
운동치료가 근위축성측삭경화증 환자 삶의 질에 미치는 영향: 예비연구
}

천윤목, 이강소, 김대열

울산대학교 서울아산병원 재활의학과

\section{The Effect of Exercise Program on Quality of Life of Patients Undergoing Amyotrophic Lateral Sclerosis: Preliminary Study}

\author{
Yoon Mok Chun, Kang Noh Lee, Dae Yul Kim \\ Department of Rehabilitation Medicine, Asan Medical Center, University of Ulsan College of Medicine, Seoul, Korea
}

\begin{abstract}
Objective: Amyotrophic lateral sclerosis (ALS) is a fatal progressive neurodegenerative disorder. The objectives of this study are to examine the effect of exercise program on the health-related quality-of-life (HRQOL) in patients with ALS Method: We reviewed ALS patients who came to the hospital's outpatient clinic from May 2014 to June 2015. The ALS patient received the hospital based exercise program, exercising 1 or 2 days/week or education of self-trained exercise program. We assessed the patients with Korean version of Amyotrophic Lateral Sclerosis Functional Rating ScaleRevised (K-ALSFRS-R) for functional capacity and SF-36 for QOL.

Results: Ten patients ( 6 males and 4 females) were evaluated for functional capacity and QOL, and four of them were reassessed. In the 2 nd evaluation, Re-evaluated patients' K-ALSFRS-R score were decreased but three of them were rated as Physical Component Score of SF-36 improved.

Conclusion: The results of our study suggest that an exercise program or education may improve HRQOL of patients with ALS.
\end{abstract}

Key Words: amyotrophic lateral sclerosis, quality-of-life, functional capacity, exercise program

\section{서 론}

운동신경원 질환은 대뇌와 척수에 위치하고 있는 운동신

Received October 18, 2017

Revised November 24, 2017

Accepted December 7, 2017

Corresponding Author: Dae Yul Kim

Department of Rehabilitation Medicine, Asan Medical Center, University of Ulsan College of Medicine, Songpa-gu, Olympic-ro 43 gil 88, Seoul 05505, Korea

Tel: 82-2-3010-3793, Fax: 82-2-3010-6964, E-mail: dykimsmart@gmail.com
경세포가 미상의 원인에 의해 퇴행성 손상 및 비가역적인 점진적인 사멸 과정을 밟는 신경계 퇴행성 질환이다. ${ }^{1}$ 근위 축성측삭경화증(Amyotrophic lateral sclerosis)은 대표적 인 운동신경원 질환으로 상위 운동신경세포(upper motor neuron)와 하위 운동신경세포(lower motor neuron)의 진 행성 손상에 의한 근력약화를 보이다 결국에는 다수가 호흡 장애로 사망하게 된다. ${ }^{2}$ 인구 10 만명당 1.5 2.7명의 발병률 을 보이는 것으로 알려져 있으며 전세계적으로는 10만명의 환자가 있는 것으로 알려져 있다. ${ }^{3}$ 근위축성측삭경화증은 한 쪽 상하지 근육의 위약으로 시작하여 다른 부위로 진행하는
Copyright $\odot$ by Korean Association of EMG Electrodiagnostic Medicine
This is an Open Access article distributed under the terms of the Creative Commons Attribution Non-Commercial License (http://creativecommons.org/licenses/by-nc/4.0) which permits unrestricted non-commercial use, distribution, and reproduction in any medium, provided the original work is properly cited. 
경우가 많으며 일부 환자에서 구음장애, 연하장애로 시작하 는 경우도 있다. ${ }^{4}$ 환자들의 평균 생존 기간은 증상 발생 후 3 5년으로 아직까지 근위축성측삭경화증의 진행을 멈출 수 있는 치료 방법은 없는 상태이나 치료효과를 공인 받은 약물 로 Riluzole이 병의 질환을 늦추고 생존율을 증가시키는 것 으로 알려져 있다. 또한 호흡보조기, 위루술, 다학제적 접근 을 통한 치료가 여러 연구에서 환자의 삶의 질 향상과 생존 기간 연장을 가능하게 한다는 것이 알려져 있다. ${ }^{6-8}$ 환자는 질병이 진행함에 따라 신체적인 움직임과 음식 먹기, 호흡기 능의 감소로 인해 활동의 제한이 발생하고 신체적으로 점차 타인에게 의존하게 되며 결국엔 모든 일상생활동작에서 타 인의 도움을 전적으로 필요하게 된다. 기능의 감소는 가족, 사회적 지지, 심리적 요인등과 함께 근위축성측삭경화증 환 자의 삶의 질을 결정하는 중요 변수로 알려져 있다. 또한 환 자의 기능상태의 악화는 환자의 우울과도 연관이 있다.?

운동치료는 근위축성 측삭경화증 환자에게 적용할 수 있 는 하나의 치료의 방법으로 받아들여지고 있으며 특히 초기, 중기의 환자에서 중등도 부하의 운동을 중등도 강도로 알맞 게 시행한 경우 환자의 기능 저하 속도 감소, 기능이 호전되 었다는 연구 결과가 있으며 삶의 질이 호전된 경우도 다수 보고되었다. ${ }^{10-12}$ 하지만 과도한 운동은 운동 후 피곤감, 근육 통증, 심한 경우 근육의 손상을 유발할 수도 있으며 일부 연 구에서는 환자의 삶의 질 향상에는 운동이 도움이 되지 못한 다는 보고도 있다. ${ }^{11,13,14}$ 환자의 신체적 상태는 삶의 질과 연 관성이 낮다는 연구도 있어 운동이 근위축성측삭경화증 환 자 삶의 질에 미치는 영향에 대해서는 아직 논쟁의 여지가 있는 실정이다. ${ }^{15}$ 더욱이 우리나라에서는 운동이 근위축성 측삭경화증 환자의 삶의 질에 미치는 영향에 대한 연구가 없 는 실정이다. 이에 본 연구는 근위축성측삭경화증 환자의 기 능과 삶의 질에 운동이 미치는 영향에 대하여 기능상태와 삶 의 질의 연속적인 평가를 통해 연구진행의 타당성을 평가하 고 연구계획의 수립과정에서 필요한 사전정보를 획득하고 자 수행된 예비연구이다.

\section{연구대상 및 방법}

\section{1) 대상군}

대상군은 2014년 5월부터 2015년 7월 사이에 본원 신 경과에서 운동 교육 및 운동 치료를 위해 재활의학과로 의 뢰되어 외래를 방문한 근위축성측삭경화증으로 진단된 환 자 중 내원 당시에 Sinaki와 Mulder가 제안한 6단계의 병
기 중 1 3단계에 해당하는 초기 및 중기 환자를 대상으로 하였다. ${ }^{16}$ 이들의 의무기록을 분석하여 환자의 임상자료 를 수집하였다. 환자들은 비침습적 양압 환기(noninvasive positive-pressure ventilation)를 적용 중에 있거나 기관절 개술 등에 의해서 구두로 대화가 어려웠던 환자는 대상군에 서 제외하였고 치료중에 병이 진행하여 비침습적 양압 환기, 기관절개술 등을 적용한 환자들의 일반적 특성을 기록하였 고 첫 증상 발현 부위에 따라서 사지형, 연수형으로 분류하 였다. 증상 발현 후 재활의학과 외래 내원시점까지를 지연 기간으로 정의하였고, 내원 시 삶의 질과 기능상태 평가를 시행하였고 근력 약화의 정도를 확인하였다. 첫 내원 후 환 자들은 운동교육 또는 운동치료를 선택하여 교육 또는 주기 적인 치료를 받았다. 환자들의 재평가는 외래에서 3 개월 간 격으로 시행되었다.

\section{2) 삶의 질 평가}

근위축성측삭경화증 환자의 삶의 질은 Ware와 Sherboune (1992)이 개발한 The Short-Form-36 Health survey 36 (SF-36)의 한국판인 SF-36을 사용하였다. SF-36 은 36문항으로 구성되어 있으며 환자가 직접 작성하여 건 강 관련(health related) 삶의 질을 포괄적으로 평가하는 도 구로 신체적 건강(physical health)과 정신적 건강(mental health) 2 개의 하부영역으로 구성되며 이는 다시 8 개의 건 강 상태 측정을 위한 세분화된 하부척도로 이루어져 있다. 각각 영역은 0 100 사이의 최종 점수로 변환되며 점수가 높 을수록 해당 영역의 삶의 질이 높은 것을 의미한다. 근위축 성측삭경화증 환자의 삶의 질을 평가하는데 있어 어떤 평가 도구를 사용하는 것이 가장 적합한가에 대한 콘센서스는 없 는 상태로 지금까지 연구들 마다 다양한 평가도구를 사용하 여 환자들의 삶의 질을 평가하고 있다. SF-36은 건강관련 삶 의 질을 평가하는데 있어 건강관리 프로그램들이 미치는 효 과를 확인하는데 유용한 장점을 가지고 있으며 근위축성 측 삭경화증 환자에서 삶의 질의 다양한 면들을 구분하여 평가 할 수 있다. ${ }^{17-20}$ 본 연구에서는 운동 치료가 환자들의 삶의 질에 미치는 영향을 확인하기 위해 위의 장점을 지닌 SF-36 을 사용하였다.

\section{3) 기능상태 평가}

Amyotrophic Lateral Sclerosis Functional Rating Scale (ALSFRS)는 근위축성측삭경화증 환자의 일상생활 수행을 위한 신체적 기능을 평가하기 위한 도구로 질병의 상태, 진 
행도, 장애 정도의 객관적 측정이 가능하며 비교적 손쉽게 적용가능하여 임상에서 널리 사용되고 있다. ${ }^{21}$ ALSFRS-R (Revised)은 ALSFRS이 호흡기능에 대한 평가가 상대적으로 약했던 단점을 보완하여 호흡기능 평가를 위한 세부항목을 강화한 것으로 ALSFRS의 특성을 유지하였다. ${ }^{22}$ ALSFRS-R 은 4항목, 12 가지 세부 항목으로 구성된 설문지 형식의 척도 로서, 상하지의 큰 근육, 작은 근육과 숨뇌 근육 및 호흡 근 육의 기능을 측정할 수 있다. 세부 항목 당 4점으로 구성되 며, 정상은 48점이며, 근육 기능의 저하 시 점수가 감소하 여 환자 상태를 객관적으로 표시할 수 있다. 본 연구에서는 ALSFRS-R의 한글판인 K-ALSFRS-R을 사용하였다.

\section{4) 운동 교육 및 치료}

처음 외래를 내원한 근위축성측삭경화증 환자는 운동 교 육 또는 외래에서 정기적인 운동 치료를 받도록 하였다. 운 동 교육은 환자들이 자가운동이 가능하도록 운동의 방법 제 시와 실습 위주로 시행하였고 환자들이 병원에 재 내원하 였을 때 반복적인 교육을 시행하여 올바른 운동 방법에 따 라서 운동을 시행할 수 있게 하였다. 병원에서 시행하는 운 동 치료는 주 1 회, 또는 2회 병원에 내원하여 치료사와 함께 30 분간 운동을 시행하도록 하였다. 운동 교육 및 치료의 내 용은 the American College of Sports Medicine (ACSM)'s Guidelines를 참고 작성하였고 관절 구축예방을 위한 신장운 동, 근력강화운동, 기능보조 증진을 위한 일반재활치료와 호 흡운동, 유산소운동으로 구성되어 있다. 신장운동은 근력약 화에 따른 하지 관절 구축 및 기능저하를 예방하기 위한 운 동을 중심으로 구성되어 있으며 기구의 사용 없이 자신의 체 중과 손을 사용하여 신장운동을 하도록 하였다. 필요 시 신 장 운동 전에 찜질, 온열치료를 적용 후에 시행하도록 하였 다. 근력강화운동은 걷기, 이동 등의 일상생활 동작 수행을 유지하기 위한 엉덩이, 대퇴부, 어깨 근육 등을 강화하는 운 동으로 구성되어 있으며 통증, 관절 구축 등의 관절 움직임 에 제한요소가 있지 않는 한 등장성 운동을 시행하였다. 근위 축성측삭경화증 환자의 특성을 고려하여 무리한 저항 운동 을 방지하기 위하여 가벼운 아령, 모래주머니, 고무줄 밴드 $\left(\right.$ Thera-Band ${ }^{\circledR}$ ) 등의 기구만을 환자에 맞게 적절하게 적용하 였다. 호흡 운동은 흥곽의 신장과 호흡근력 강화운동으로 구 성되어 있으며 다양한 호흡법과 객담 배출을 위한 호기근의 운동도 포함하였고 폐의 탄력성 유지 운동, 기도 분비물 제 거, 비침습적 호흡기 관리를 위한 호흡재활치료도 함께 시행 하였다. 운동의 강도는 근위축성측삭경화증 단계와 근력의
약화 정도를 고려하여 환자에게 적용하였는데 근력 약화가 심하지 않고 독립적인 보행이 가능하며 일상생활 수행에 어 려움이 없는 환자인 경우 호흡운동, 신장운동, 근력강화운동 을 중심으로 교육하였으며 특정 근육군에 심한 근력약화로 일상생활에 제한이 있는 환자는 호흡운동, 신장운동, 유산소 운동에 좀더 집중하도록 교육하였다. 자가 운동을 위한 운동 교육과 병원에서 시행하는 운동 치료는 그 내용과 방법에는 차이가 없으나 치료사와 함께하는 운동 치료는 운동의 강도 및 구성을 환자의 상태에 맞게 바로 변경해 적용 가능하며 꾸 준하게 운동을 유지할 수 있는 장점이 있다. 운동 교육의 내 용은 환자가 스스로 시행 시 30 분에서 45 분정도 시간이 소요 되는 구성으로 되어 있으며, 환자의 견딤, 운동에 대한 반응 과 하루 일과 등을 고려하여 2 3회로 나누어 시행하도록 교 육하였다. 운동 교육과 운동 치료를 받는 모든 환자에게 운동 방법과 프로그램에 대한 안내자료를 배부하여 지속적인 운 동이 시행될 수 있게 하였고(Table 1) 더불어 규칙적으로 걷 기, 수영, 자전거타기 등의 유산소운동을 자가로 시행하는 것 이 필요함을 교육하였다.

\section{결 과}

연구 대상자는 총 10 명으로(남성 6, 여성 4)으로 평균 연 령은 $53.6 \pm 10.4$ 세이었으며 증상의 시작은 9명이 사지형 이었다. 위루관을 가진 환자는 없었다. 증상 발현 후 재활 의학과 외래 내원까지의 지연 기간은 평균 15.9 개월이었다 (Table 2). 10명의 환자 중 3명이 병원에서 시행하는 운동치

Table 1. Brief Summary of Exercise Program Brochure for ALS Patients

\begin{tabular}{|c|c|}
\hline 운동 프로그램의 구성 & 운동 방법 및 주의사항 \\
\hline 신장(스트레칭)운동 & $\begin{array}{l}\text { · 반동을 주지 않고 느리고 부드럽게 시행한다. } \\
\text { · 통증이 없는 범위까지만 시행한다. } \\
\text { · 운동범위는 점진적으로 늘려간다. } \\
\text { · 한 동작을 } 15 \text { 초 30초간 유지한다. } \\
\text { ·찜질, 온열치료 후에 하면 더욱 효과적이다. } \\
\text { (※) 과도한 스트레칭 금지 }\end{array}$ \\
\hline 근력강화운동 & $\begin{array}{l}\text { · 준비운동(신장운동) 후 근력운동을 시행한다. } \\
\text { · 운동 중에 숨을 참지 않는다. } \\
\text { · 운동과 휴식시간을 동일하게 한다. } \\
\text { · 고무줄 밴드나 모래주머니 같은 도구를 사용하면 더욱 } \\
\text { 효과적이다. } \\
\text { (※) 피로감을 주지 않는 범위 내에서 시행 }\end{array}$ \\
\hline 호흡운동 & $\begin{array}{l}\text { · 복식 보다 흉식호흡에 더욱 집중한다. } \\
\text { · 호기(날숨)보다 흡기(들숨)운동에 더욱 집중한다. } \\
\text { · 숨은 코로 마시고 작은 입으로 내쉰다. } \\
\text { (※) 긴 심호흡을 자주하세요 }\end{array}$ \\
\hline
\end{tabular}


Table 2. Characteristics of Study Patients

\begin{tabular}{rrrrrrr}
\hline \hline No & Age & Sex & Type & K-ALSFRS-R (1 $\left.{ }^{\text {st }}\right)$ & Exercise type $\begin{array}{c}\text { Time between onset and 1 } \\
\text { interview (months) }\end{array}$ \\
\hline 1 & 53 & F & Spinal & 38 & Education & 9 \\
2 & 78 & F & Bulbar & 45 & Education & 16 \\
3 & 52 & M & Spinal & 37 & Exercise & 5 \\
4 & 52 & M & Spinal & 40 & Education & 6 \\
5 & 50 & M & Spinal & 42 & Education & 18 \\
6 & 37 & M & Spinal & 45 & Education & - \\
7 & 57 & F & Spinal & 36 & Education & 5 \\
8 & 47 & M & Spinal & 46 & Exercise & 35 \\
9 & 51 & F & Spinal & 22 & Education & 31 \\
10 & 59 & M & Spinal & 18 & \\
\hline
\end{tabular}

K-ALSFRS-R: The Korean version of Amyotrophic Lateral Sclerosis Functional Rating Scale-Revised

료를 선택하였다. 10 명의 환자 중 4 명의 환자에서 재평가가 이루어졌으며 이 중 3 명은 운동교육, 1 명은 병원에서 운동 치료를 받았다. 첫 번째 평가에서 환자 10 명의 K-ALSFRS-R score 평균은 36.9 \pm 9.6점이었다(Table 3). 10명의 환자 중 K-ALSFRS-R의 30점 이상인 환자는 8명이었으며 이중 5 명은 40점 이상의 점수를 보였다. SF-36을 사용하여 평 가한 환자의 삶의 질 중 신체적 건강 항목(physical health component)의 평균은 $48.5 \pm 33.1$ 이었다. 이를 건강한 정상인을 기준으로 하여 평가한 정상 기준 점수는(NBS: Norm-based scoring, Mean = 50, SD = 10) $41.0 \pm 9.7$ 이 었으며 영역별 점수는 신체적 기능 $62.0 \pm 34.8$, 신체적 역 할 제한 $39.2 \pm 46.4$, 통증 $49.5 \pm 27.9$, 일반적 건강 43.0 \pm 16.5 이었다. 정신적 건강(mental health component) 항목의 평균은 $48.9 \pm 29.5$ 이었으며 정상 기준 점수(NBS) 는 $38.8 \pm 8.4$ 이었다. 각 항목은 감정적 역할제한 $45.0 \pm$ 45.8 , 활력 $47.2 \pm 18.2$, 정신건강 $56.9 \pm 24.2$, 사회적 기 능 $46.3 \pm 25.7$ 이었다.

재평가를 받은 4명 환자의 첫 평가 K-ALSFR-R score 평 균은 $42.3 \pm 4.5$ 이었으며 3개월 후 재평가에서는 $40.25 \pm$ 4.3점이었다(Table 4). SF-36을 이용하여 평가한 환자의 삶 의 질 중 신체적 건강의 평균 점수는 $47.2 \pm 33.5$ 에서 63.4 \pm 27.3 으로 변화하였고 이 점수의 정상 기준 점수(NBS) 평 균은 각각 $40.2 \pm 12.6$ 과 $48.3 \pm 3.9$ 로 나타났다. 정신적 건강의 평균 점수는 $52.4 \pm 25.7$ 에서 $47.3 \pm 25.7$ 로 변화 하였고 정상 기준 점수 평균은 $41.7 \pm 10.1$ 과 $33.0 \pm 10.8$ 이었다(Fig. 1).
Table 3. Mean of Quality of Life and Functional Capacity of $1^{\text {st }}$ Interview

\begin{tabular}{llc}
\hline \hline \multicolumn{1}{c}{ Variable } & $\begin{array}{c}1^{\text {st }} \text { Interview } \\
(\mathrm{n}=10)\end{array}$ \\
\hline SF-36 & $\begin{array}{l}\text { Physical Functioning } \\
\text { Role Limitations Due to Physical Health }\end{array}$ & $39.0 \pm 34.8$ \\
& Role Limitations Due to Emotional Problems & $45.0 \pm 46.6$ \\
Energy/Fatigue & $47.2 \pm 18.2$ \\
Emotional Well Being & $56.9 \pm 24.2$ \\
Social Functioning & $46.3 \pm 25.7$ \\
Pain & $49.5 \pm 27.9$ \\
General Health & $43.0 \pm 16.5$ \\
Physical Component Score & $48.5 \pm 33.1$ \\
Physical Component Score (NBS) & $41.0 \pm 9.7$ \\
Mental Component Score & $48.9 \pm 29.5$ \\
Mental Component Score (NBS) & $38.8 \pm 8.4$ \\
K-ALSFRS-R & $36.9 \pm 9.6$ \\
\hline
\end{tabular}

SF-36: The Short Form (36) Health Survey, 1st Interview: Interview before receiving exercise program or education, Values are mean \pm standard deviation. Physical Component Score is composed of Physical Functioning, Role Limitations Due to Physical Health, Pain and General Health, Mental Component Score is composed of Role Limitations Due to Emotional Problems, Energy/Fatigue, Emotional Well Being, and Social Functioning, NBS: Norm-based scoring (Mean $=50, \mathrm{SD}=10$ )

\section{고 찰}

근위축성측삭경화증 환자에서 병의 진행을 막을 방법은 아직까지 없는 상태로 환자들에게 적용할 수 있는 치료법은 병의 진행에 따른 신체적 기능의 악화를 가능한 늦추고 감소 한 신체적 기능에 대한 다양한 지지적(supportive) 간호를 제공하는 것이다. 환자에게 적용된 치료와 간호의 효율성 및 효과를 평가하기 위해서 이들의 삶의 질을 평가하는 것은 필 수적이며 ALSFR-R로 평가된 기능의 정도는 SF-36 등의 건 강 관련(health related) 삶의 질 평가 도구와 의미 있는 상 
Table 4. Difference of K-ALSFRS-R Score between $1^{\text {st }}$ and $2^{\text {nd }}$ Interview in Follow Up Patients

\begin{tabular}{|c|c|c|c|c|c|c|c|c|}
\hline \multirow{2}{*}{$\mathrm{K}-\mathrm{ALSFRS}-\mathrm{R}$} & \multicolumn{2}{|c|}{ No. 2 patient } & \multicolumn{2}{|c|}{ No. 5 patient } & \multicolumn{2}{|c|}{ No. 7 patient } & \multicolumn{2}{|c|}{ No. 8 patient } \\
\hline & $1^{\text {st }}$ & $2^{\text {nd }}$ & $1^{\text {st }}$ & $2^{\text {nd }}$ & $1^{\text {st }}$ & $2^{\text {nd }}$ & $1^{\text {st }}$ & $2^{\text {nd }}$ \\
\hline 1. Speech & 2 & 2 & 4 & 3 & 3 & 4 & 4 & 4 \\
\hline 2. Salivation & 4 & 2 & 4 & 4 & 4 & 4 & 4 & 4 \\
\hline 3. Swallowing & 3 & 3 & 4 & 3 & 3 & 4 & 4 & 4 \\
\hline 4. Handwriting & 4 & 4 & 3 & 2 & 2 & 3 & 3 & 3 \\
\hline 5. Cutting food and handling utensils & 4 & 4 & 3 & 3 & 3 & 2 & 4 & 3 \\
\hline 6. Dressing and hygiene & 4 & 4 & 2 & 2 & 2 & 2 & 3 & 3 \\
\hline 7. Turning in bed and adjusting bed clothes & 4 & 4 & 2 & 3 & 3 & 4 & 4 & 4 \\
\hline 8. Walking & 4 & 3 & 4 & 3 & 3 & 3 & 4 & 4 \\
\hline 9. Climbing stairs & 4 & 4 & 4 & 3 & 3 & 3 & 4 & 4 \\
\hline 10. Dyspnea & 4 & 4 & 4 & 3 & 3 & 4 & 4 & 4 \\
\hline 11. Orthopnea & 4 & 4 & 4 & 3 & 3 & 4 & 4 & 4 \\
\hline 12. Respiratory insufficiency & 4 & 4 & 4 & 4 & 4 & 4 & 4 & 4 \\
\hline Total & 45 & 42 & 42 & 36 & 36 & 41 & 46 & 45 \\
\hline
\end{tabular}

K-ALSFRS-R includes 12 questions that can have a score of 0 to 4 , A score of 4 would indicate full function.
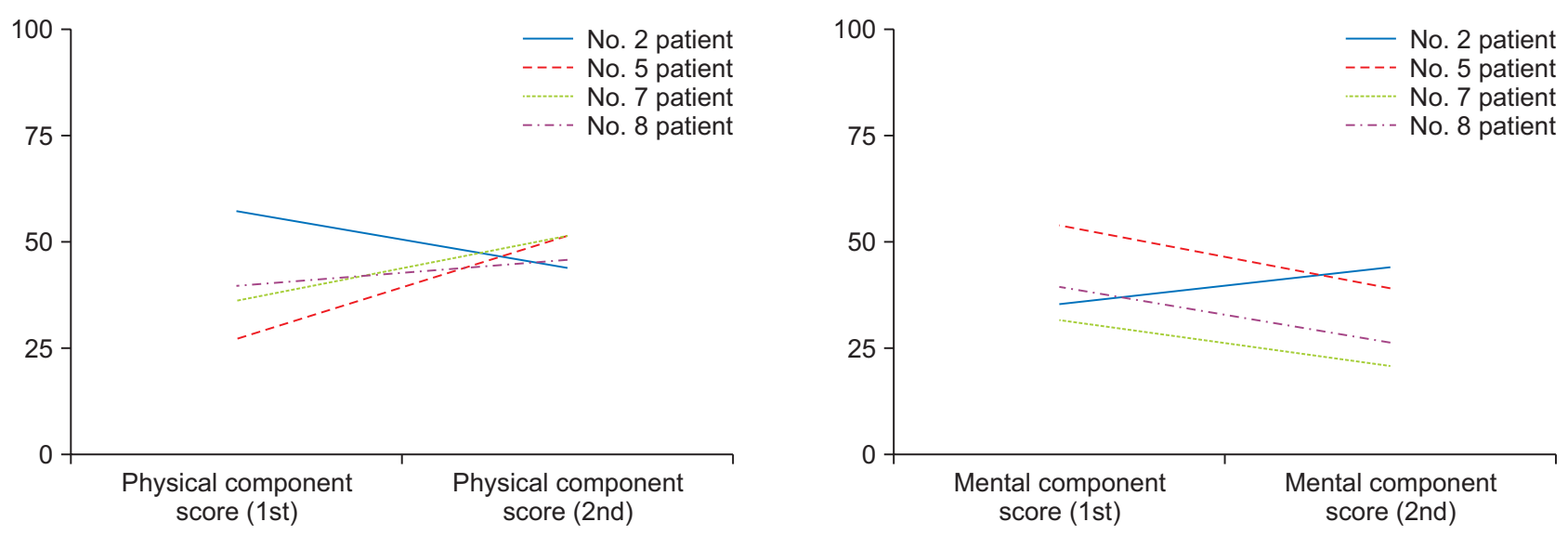

Fig. 1. Change of quality of life between 1 st and 2 nd interview in follow up patients.

관관계를 보이는 것으로 알려져 있다. ${ }^{22,23}$ ALSFR-R에서 평 가된 신체적 기능이 감소할 때 SF-36의 삶의 질 역시 저하되 는 경향을 보이나 일부 연구에서는 SF-36의 항목 중 신체적 건강 항목에서만 신체적 기능과 의미 있는 상관관계가 나타 나는 것으로 알려져 있기도 하다. ${ }^{20,24,25}$ 본 연구에서 10 명 환 자들의 초기 K-ALSFR-R 평균은 $36.9 \pm$ 9.6점이었다. 재평 가를 받은 4명 환자의 첫 평가 K-ALSFR-R 평균은 $42.3 \pm$ 4.5 점으로 10 명의 평균보다 상대적으로 높은 신체적 기능을 유지한 상태였다. 첫 평가 이후 3개월 시점에 시행된 재평가 에서는 K-ALSFR-R 평균은 $40.25 \pm$ 4.3점으로 3개월 기 간 동안 환자들의 신체 기능 저하가 확인되었다. 근위축성측 삭경화증 질병 진행도와 예후를 평가한 선행연구에서 환자 들의 K-ALSFR-R 값이 평균 매달 0.73점 감소했는데 본 연 구의 환자들에서 기능감소는 선행 연구에서 예상되는 정도 에 상응하였다. ${ }^{4,22} \mathrm{~K}-\mathrm{ALSFR}-\mathrm{R}$ 값이 감소했음에도 SF-36으
로 평가한 삶의 질 중 신체적 건강 항목의 평균 점수는 47.2 \pm 33.5 에서 $63.4 \pm 27.3$ 으로 오히려 상승하였다. 근위축 성측삭경화증 환자에서 저항성 근력 운동을 시행한 군에서 SF-36의 신체적 건강 항목에서 의미 있는 개선을 확인한 선 행 연구와 유사하게 본 연구에서도 환자의 신체적 기능의 악 화가 진행되었지만 신체적 건강 항목에서 삶의 질의 증진 이 있었으며 이는 환자들이 참여한 운동 프로그램에 의한 효 과로 생각할 수 있겠다. ${ }^{11}$ 더하여 이 같은 운동의 효과는 질 병의 초기, 중기 단계에서 효과가 있는 것으로 알려져 있는 데 본 연구에 참여한 환자의 대부분이 기본적인 일상생활능 력(activity of daily living)이 유지된 초기 및 중기의 환자 이었다. 반면 재평가된 4 명의 환자의 SF-36 정신적 건강 항 목의 평균은 $52.4 \pm 25.7$ 에서 $47.3 \pm 25.7$ 로 감소하였다. 근위축성측삭경화증 환자에서 SF-36의 정신적 건강 항목 의 악화는 신체적 기능의 저하와 직접적으로 연관되어 있기 
보다는 신체적 기능의 저하에 따른 우울감(depression) 증 가에 따라 영향을 받는 것으로 알려져 있으며 ${ }^{24,25}$ 환자 다수 가 경험하는 불안감(anxiety)도 삶의 질을 악화시키는 것으 로 알려져 있다. 특히 본 연구에 참여한 환자처럼 질병을 진 단받거나 진단 후 얼마 지나지 않은 시점에서 환자들은 높 은 수준의 불안감을 겪게 되는 것으로 알려져 있어 ${ }^{18,26}$ 이 같 은 요소들의 복합적 영향에 의해 정신적 건강 항목이 악화 되었을 것으로 생각된다. 이 같은 점을 고려하여 환자에게 적절한 치료를 제공하는 것이 중요하겠는데 물리, 작업, 언 어 치료사, 영양사, 사회복지사를 기본으로 포함한 다학제적 (Multidisciplinary) 치료를 적용한 경우 SF-36의 정신적 건 강 항목에서 삶의 질의 호전을 보일 수 있다. ${ }^{27}$ 하지만 삶의 질 평가 도구들은 환자의 기능 상태에 치우친 경향을 보이는 경우가 다수이며 특히 건강 관련(health related) 삶의 질 평 가 도구의 경우 외적으로 확인되는 환자의 건강 상태를 기본 으로 삶의 질을 평가하게 되어 개개인 환자들의 삶의 질을 정확히 반영하기 어렵다는 한계점을 가진다. ${ }^{28,29}$

본 연구의 제한점은 다음과 같다. 대상자가 서울 소재 종 합병원 외래로 내원했던 환자로 제한되었으며 그 대상자 수 가 적었다는 점이다. 외래로 내원했으나 연구에 포함되지 않 은 환자들도 다수 있었는데 이 경우 병기가 진행되어 운동치 료가 불가한 경우가 일부 있었으나 다수는 근위축성측삭경 화증을 진단을 받은 직후, 심리적 불안감과 질병에 대한 부 정으로 운동 치료에 참여하지 않거나 재진단을 위해 진료받 는 병원을 변경하는 경우였다. 본 예비연구는 후향적 연구로 환자들의 운동의 횟수, 시간 등 환자들 간의 운동의 양과 질 을 일정하게 관리하지 못한 제한점이 있다. 이에 향후 연구 에서는 심리적인 어려움을 겪을 환자들에게 의료진의 심리 적인 지지를 상황에 맞게 제공하는 것이 중요하겠으며 운동 치료 기간 동안 환자들의 운동 참여도를 관리하고 유지하기 위한 모니터링 계획을 수립하는 것이 중요하겠다.

\section{결 론}

초기 및 중기 근위축성측삭경화증 환자에서 신체적 기능 의 감소에도 불구하고 지속적인 운동 교육과 치료를 통해서 신체적 건강 항목의 삶의 질의 향상 또는 저하의 정도를 줄 일 수 있을 것으로 판단된다. 다만 운동 교육, 운동 치료의 적용으로 신체적 건강, 혹은 전반적인 삶의 질에 긍정적인 효과를 얻을 수 있더라도 정신적 건강과 관련된 삶의 질에 도움을 주기 위해서는 다학제적 치료 방법을 동시에 적용하
여 우울감, 불안감 등에 의한 삶의 질 저하를 예방하는 것이 필요하겠다.

\section{References}

1. Shin J-Y, Lee K-W: Diagnosis and management of amyotrophic lateral sclerosis. J Korean Med Assoc 2015: 58: 131138

2. de Almeida JP, Silvestre R, Pinto AC, de Carvalho M: Exercise and amyotrophic lateral sclerosis. Neurol Sci 2012: 33: 9-15

3. Leigh PN, Abrahams S, Al-Chalabi A, Ampong MA, Goldstein LH, Johnson J, et al: The management of motor neurone disease. J Neurol Neurosurg Psychiatry 2003: 74 Suppl 4: iv32iv 47

4. Baek W, Park A, Kim HY, Kim SH: Amyotrophic Lateral Sclerosis in Korea: Clinical Characteristics and Prognostic Factors. J Korean Neurol Assoc 2011: 29: 16-24

5. Bensimon G, Lacomblez L, Meininger V: A controlled trial of riluzole in amyotrophic lateral sclerosis. ALS/Riluzole Study Group. N Engl J Med 1994: 330: 585-591

6. Traynor BJ, Alexander M, Corr B, Frost E, Hardiman O: Effect of a multidisciplinary amyotrophic lateral sclerosis (ALS) clinic on ALS survival: a population based study, 1996-2000. J Neurol Neurosurg Psychiatry 2003: 74: 1258-1261

7. Miller RG, Jackson CE, Kasarskis EJ, England JD, Forshew D, Johnston W, et al: Practice parameter update: the care of the patient with amyotrophic lateral sclerosis: drug, nutritional, and respiratory therapies (an evidence-based review): report of the Quality Standards Subcommittee of the American Academy of Neurology. Neurology 2009: 73: 1218-1226

8. Bourke SC, Tomlinson M, Williams TL, Bullock RE, Shaw PJ, Gibson GJ: Effects of non-invasive ventilation on survival and quality of life in patients with amyotrophic lateral sclerosis: a randomised controlled trial. Lancet Neurol 2006: 5: 140-147

9. Simpson EP, Appel SH: "Individual and health-related quality of life assessment in amyotrophic lateral sclerosis patients and their caregivers" by Lo Coco G, Lo Coco D, Cicero V, Oliveri A, Lo Verso G, Piccolo F, La Bella V. J Neurol Sci 2005: 238: 1-2

10. Chen A, Montes J, Mitsumoto H: The role of exercise in amyotrophic lateral sclerosis. Phys Med Rehabil Clin N Am 2008: 19: 545-557, ix-x

11. Bello-Haas VD, Florence JM, Kloos AD, Scheirbecker J, Lopate G, Hayes SM, et al: A randomized controlled trial of resistance exercise in individuals with ALS. Neurology 2007: 
68: 2003-2007

12. Drory VE, Goltsman E, Reznik JG, Mosek A, Korczyn AD: The value of muscle exercise in patients with amyotrophic lateral sclerosis. J Neurol Sci 2001: 191: 133-137

13. van Groenestijn AC, van de Port IG, Schroder CD, Post MW, Grupstra HF, Kruitwagen ET, et al: Effects of aerobic exercise therapy and cognitive behavioural therapy on functioning and quality of life in amyotrophic lateral sclerosis: protocol of the FACTS-2-ALS trial. BMC neurology 2011: 11: 70

14. Lewis M, Rushanan S: The role of physical therapy and occupational therapy in the treatment of amyotrophic lateral sclerosis. NeuroRehabilitation 2007: 22: 451-461.

15. Chio A, Gauthier A, Montuschi A, Calvo A, Di Vito N, Ghiglione $\mathrm{P}$, et al: A cross sectional study on determinants of quality of life in ALS. J Neurol Neurosurg Psychiatry 2004: 75: 1597-1601

16. Dal Bello-Haas V, Kloos AD, Mitsumoto H: Physical therapy for a patient through six stages of amyotrophic lateral sclerosis. Phys Ther 1998: 78: 1312-1324

17. Lemoignan J, Ells C: Amyotrophic lateral sclerosis and assisted ventilation: How patients decide. Palliat Suppor Care 2010: 8: 207-213

18. Norris L, Que G, Bayat E: Psychiatric Aspects of Amyotrophic Lateral Sclerosis (ALS). Curr Psychiatry Rep 2010: 12: 239245

19. Sanchez-Lopez CR, Perestelo-Perez L, Ramos-Perez C, Lopez-Bastida J, Serrano-Aguilar P: [Health-related quality of life in patients with amyotrophic lateral sclerosis]. Neurologia (Barcelona, Spain) 2014: 29: 27-35

20. Jenkinson C, Fitzpatrick R, Swash M, Peto V: The ALS Health Profile Study: quality of life of amyotrophic lateral sclerosis patients and carers in Europe. J Neurol 2000: 247: 835-840

21. Cedarbaum JM, Stambler N: Performance of the Amyo- trophic Lateral Sclerosis Functional Rating Scale (ALSFRS) in multicenter clinical trials. J Neurol Sci 1997: 152 Suppl 1: S1-S9

22. Cedarbaum JM, Stambler N, Malta E, Fuller C, Hilt D, Thurmond B, et al: The ALSFRS-R: a revised ALS functional rating scale that incorporates assessments of respiratory function. BDNF ALS Study Group (Phase III). J Neurol Sci 1999: 169: $13-21$

23. Neudert C, Wasner M, Borasio GD: Individual quality of life is not correlated with health-related quality of life or physical function in patients with amyotrophic lateral sclerosis. J Palliat Med 2004: 7: 551-557

24. Tramonti F, Bongioanni P, Di Bernardo C, Davitti S, Rossi B: Quality of life of patients with amyotrophic lateral sclerosis. Psychol Health Med 2012: 17: 621-628

25. Korner S, Kollewe K, Abdulla S, Zapf A, Dengler R, Petri S: Interaction of physical function, quality of life and depression in Amyotrophic lateral sclerosis: characterization of a large patient cohort. BMC neurology 2015: 15: 84

26. Vignola A, Guzzo A, Calvo A, Moglia C, Pessia A, Cavallo E, et al: Anxiety undermines quality of life in ALS patients and caregivers. Eur J Neurol 2008: 15: 1231-1236

27. Van den Berg JP, Kalmijn S, Lindeman E, Veldink JH, de Visser M, Van der Graaff MM, et al: Multidisciplinary ALS care improves quality of life in patients with ALS. Neurology 2005: 65: 1264-1267

28. Guyatt GH, Cook DJ: Health status, quality of life, and the individual. JAMA 1994: 272: 630-631

29. Cohen SR, Mount BM, Tomas JJ, Mount LF: Existential wellbeing is an important determinant of quality of life. Evidence from the McGill Quality of Life Questionnaire. Cancer 1996: 77: 576-586 